\title{
Social network type and subsequent cognitive health among older Europeans
}

\author{
Ella Cohn-Schwartz, ${ }^{1}$ (1) Michal Levinsky, ${ }^{2}$ and Howard Litwin ${ }^{2}$ \\ ${ }^{1}$ Department of Public Health, Faculty of Health Sciences, Ben-Gurion University of the Negev, Be'er Sheva, Israel \\ ${ }^{2}$ Israel Gerontological Data Center, Paul Baerwald School of Social Work, The Hebrew University of ferusalem, Mount Scopus, 91905 ferusalem, Israel
}

ABSTRACT

Objectives: One's personal social network constitutes a contextual framing factor for late-life cognitive function. This study examined the association between network type at baseline and changes in three cognitive measures: immediate recall, delayed recall, and fluency, two years hence, among Europeans aged 50 and older.

Participants: Data were taken from Waves four and five of the Survey of Health, Ageing, and Retirement in Europe of adults aged 50 and above $(N=50,071)$.

Measurements: The latent class analysis was applied to a set of criterion variables. The procedure yielded five distinct network types: multi-tie (6\%), family-rich (23\%), close-family (49\%), family-poor (12\%), and friendenhanced $(10 \%)$. The network types were then regressed on the cognition measures at follow-up, controlling for the respective baseline cognition scores, as well as for age, gender, education, self-rated health, mobility difficulty, and country.

Results: Respondents in family-poor network types had poorer cognition scores at follow-up, compared to those in the modal close-family network, while those in multi-tie networks had consistently better scores. The familyrich network and the friend-enhanced network also had a somewhat better cognitive function.

Conclusions: Having varied sources of network ties, e.g. friendship ties and/or several types of family relationships, is beneficial to the cognitive health of older adults over time. Networks based mainly on ties with relatives other than spouse and children, on the other hand, have poorer cognitive outcomes. Older people in this latter group face an increased risk for cognitive decline and should receive assistance in enhancing their interpersonal environments.

Key words: social networks, cognitive function, volunteering, family networks, SHARE

\section{Introduction}

Cognitive decline is a major health concern in later life (Deary et al., 2009). It is associated, moreover, with reduced functional capacity, loss of independence (Luppa et al., 2009), depression (Aichele and Ghisletta, 2018), and mortality (Schupf et al., 2005). Therefore, identification of the factors that influence cognitive performance in older age is an increasingly important task and should be a public health priority as well.

Social embeddedness, that is, the ties that people variously maintain, has long been identified as a factor that is related to cognitive function (Crooks et al., 2008; Hertzog et al., 2009; Kelly et al., 2017).

Correspondence should be addressed to: Ella Cohn-Schwartz, Department of Public Health, Faculty of Health Sciences, Ben-Gurion University of the Negev, Be’er Sheva, Israel. Phone: +972 54 7293397. Email: ellasch@bgu .ac.il. Received 12 May 2020; revision requested 06 Aug 2020; revised version received 10 Aug 2020; accepted 01 Sep 2020. First published online06 Nov 2020
However, most existing studies utilize single indicators of the interpersonal social environment, and these provide only a partial understanding of people's social lives. In contrast, the current study examines the association between a composite measure of social embeddedness, namely, the notion of social network type, and changes in cognitive performance over time.

The cognitive enrichment hypothesis posits that a socially enriched environment can help preserve and improve cognitive function in old age (Hertzog et al., 2009). This approach maintains that the brains of older adults can adapt to compensate for neural changes that occur late in life (Park and ReuterLorenz, 2009) and that this adaptation is influenced by one's social context and personal behavior. More specifically, interactions with other people can act as a form of mental stimulation, as proposed by the "use it or lose it" hypothesis (Hultsch et al., 1999). 
Indeed, interaction with children and friends, more than with spouses and relatives, was found in one study to be related to a better cognitive function over time, presumably because such ties provide more novel and complex interactions (Schwartz and Litwin, 2019). Another study revealed that social activities, such as volunteering, were related to a lower risk of progression from mild-to-severe cognitive impairment among mildly impaired adults (Hughes et al., 2013).

However, the social environments in which individuals' are embedded are actually complex social constructs that reflect a number of different characteristics. Wenger (1991) first addressed the composite characterization of nature and the extent of one's interpersonal environment by means of the term "social network type." The network type construct has been subsequently employed in a range of settings (Fiori et al., 2007).

Discerning different types of social networks permits one to analyze how the complex aspects of social interconnectedness can interplay with health and well-being in late life. Network types have been shown to predict mortality (Litwin and Shiovitz-Ezra, 2006), functional dependency (Doubova et al., 2010), physical health (Litwin, 1998), morale (Litwin, 2001), anxiety, loneliness and happiness (Litwin and Shiovitz-Ezra, 2011), and depressive symptomatology (Fiori et al., 2006). Moreover, the research literature points to certain prototypical network constellations that prevail in older age, and these include "diverse," "family-focused," "friend-focused," and "restricted" network types. Persons embedded in "diverse" networks have been found to have a better well-being than those in more "restricted" networks (Djundeva et al., 2018). Family-based networks also tend to be associated with better states of well-being (Litwin et al., 2020; Litwin and Stoeckel, 2014).

The examination of network typologies can provide a different and much-needed perspective on the social concomitants of cognitive functioning. Based on the cognitive enrichment hypothesis, networks that constitute a broadening environment, that is, one that is composed of a diverse range of social relationships and activities, are likely to be the most beneficial. Along these lines, a study based on a sample of older adults from the Netherlands found that complex networks, i.e. those containing a greater variety of personal relationship types, were indeed linked over time to less cognitive decline (Ellwardt et al., 2015). Another study found that social integration, assessed as marital status, doing volunteer activity, and frequent contact with children, parents, and neighbors, was related to better memory over time (Ertel et al., 2008).
Nevertheless, knowledge regarding the effects of different network types on late-life cognitive function is still somewhat limited. One study, based on older Korean adults, found that there was a less cognitive decline among those respondents who were embedded in two particular network types ("diverse/couple network" and "congregant network"), compared to those in the "widowed network" type (Kim and Lee, 2019). This particular outcome might differ in other populations, however. For example, relatives and volunteer activity might be more relevant to older adults in Europe (Ertel et al., 2008; Litwin and Stoeckel, 2014).

Based on this brief review of the literature, the current study sets out to examine the associations between social network types and cognition in late life. It uses two data points to assess the effects of network type on subsequent cognition. Since the cognitive function is generally maintained and reinforced through interpersonal stimulation and relationship novelty, social networks that have a greater diversity of social ties might also provide greater cognitive stimulation. Furthermore, those networks that incorporate social activities outside of one's close familial circles, such as those that are reflected in friendship ties and volunteer activities, might also provide greater cognitive stimulation. The current analysis hypothesizes, therefore, that older adults who are embedded in networks with more diverse ties and those that have a larger share of friendship ties and social activities, at baseline, are associated with better cognitive performance at follow-up, compared to their age-peers who are embedded in more restricted network types.

\section{Methods}

\section{Data and participants}

Data were taken from the Survey of Health, Ageing, and Retirement in Europe (SHARE), a crossnational panel survey of community-dwelling adults aged 50 and above and their partner of any age. The survey was conducted by trained interviewers at the respondent's home, using a computer-assisted personal interview (CAPI) (Börsch-Supan et al., 2013). The study sample relates to the 50,071 participants who took part in the survey in Wave 4 (2011), the data from which served as the baseline for the present analysis, and resided in the countries that participated again in Wave 5 of SHARE (2013). Of these respondents, 36,088 persons also took part in Wave 5 of the survey (2013), which provided the follow-up data on cognitive function. Participants from the following 13 European countries took part in both of the waves and were thus included in the 
present study: Austria, Germany, Sweden, Netherlands, Spain, Italy, France, Denmark, Switzerland, Belgium, Czech Republic, Slovenia, and Estonia.

\section{Variables}

Cognitive function was measured using three tests: immediate recall, delayed recall, and fluency. These tests are sensitive to aging-related decline (Dewey and Prince, 2005). In immediate recall, the interviewer reads a list of ten works and respondents are asked to repeat these words. The measure ranges between 0 and 10, with higher scores indicating better recall. For delayed recall, the respondents are asked to repeat these same words after a ten minute hiatus in the interview. Thus, the delayed recall measure also has a range of $0-10$. Taken together, the immediate and delayed recall tasks test short-term verbal learning and memory as well as information retention (Dal Bianco et al., 2013) and can also be used as a measure of episodic memory (Cheke and Clayton, 2013). The third cognitive measure - fluency - was tapped by asking participants to name as many animals as they can within a span of one minute. Due to a small number of outliers in the current sample, scores greater than 45 were re-coded to 45 . The fluency test is considered to be a measure of executive functioning, but also reflects other processes, such as semantic memory and processing speed (Clark et al., 2009; Haugrud et al., 2011).

\section{Social network variables}

The composition of the respondents' close social networks, and particularly the presence of friends and relatives in the network, was measured by means of a name generator inventory. Using this probe, participants were asked to name up to six people with whom they discussed important matters in the previous 12 months. Following the naming of these individuals, termed here as confidants, the participants were asked whether there was anyone else who was important for any other reason. The maximum number of confidants, therefore, was seven. Respondents were then asked about their role relationship with each of the named confidants, i.e. whether they were a spouse, child, friend, etc. Based on this information, we created a dichotomous variable indicating whether the respondent had a relative in his or her close network, and another to indicate whether there was a friend in the close network.

Marital status was based on a dichotomous variable (married $\backslash$ not married). The number of children was divided into three categories: not having children, having 1-2 children, and having 3 or more children. The last of the social network variables tapped another form of social activity outside of one's family, namely volunteering. It was obtained by asking respondents whether they had engaged in volunteer activities in the previous 12 months (yes\no).

\section{Social network type: latent class indicator variables}

The social network types were derived through latent class analysis (LCA), a tool that has been proved to be effective in finding empirical classes without previous assumptions about the number and characteristics of the classes. The analysis identifies a categorical latent variable, with the categories reflecting significant differences between the classes. Each individual in the sample has a high probability of being classified in one of the classes, and a low probability of being classified in the others.

We conducted the LCA analysis with the Mplus program version 8.2 , based on the respondents who participated in Wave 4 and provided information about their social networks, family ties, and volunteering activities. The five social network variables mentioned earlier were entered into the model (the presence of friends in the social network, the presence of relatives in the social network, marital status, number of children, and engagement in volunteer activities). The procedure began from a model with a low number of classes (2) and increased the number of classes until no improvement in the model fit indices was achieved. We relied on the Bayesian information criterion (BIC), adjusted Bayesian information criterion (ABIC), bootstrapped likelihood ratio test (BLRT), and Lo-Mendall-Rubin (LMR) to determine the optimal number of classes, as recommended in previous research (Nylund et al., 2008). The smallest AIC and BIC scores were used as criteria for the goodness of fit. The LMR and BLRT significant tests were used to assess whether the right number of classes was chosen.

The fit indices of the LCA models in the current analysis are shown in Table 1 . The BIC and adjusted BIC decreased until the 5-class model and then increased for the 6-class model, indicating that the 5-class model fit the data best. The BLRT test comparing the 4-class and the 5-class models was significant, while the test comparing the 5 -class and 6-class models did not converge, adding additional support to the fit of a 5-class model. The LMR test comparing the 5-class model to the 6-class model was significant, although with a $p$-value closer to 0.05 than the lower $p$-value of the LMR comparing of the 4-class and 5-class models. Thus, most of the models indicate a better fit for the 5-class model. Based on these measures, we selected the 5-class 
Table 1. Fit indices of latent class analysis on network types estimated

\begin{tabular}{|c|c|c|c|c|}
\hline & & & BLRT & LMR \\
\hline ESTIMATED CLASSES & BIC & $\mathrm{ABIC}$ & $p-V A L U E$ & $p-V A L U E$ \\
\hline 2 & 318605.31 & 318563.99 & $<0.001$ & $<0.001$ \\
\hline 3 & 317414.84 & 317351.28 & $<0.001$ & $<0.001$ \\
\hline 4 & 317278.00 & 317192.19 & $<0.001$ & $<0.001$ \\
\hline 5 & 317272.48 & 317164.43 & $<0.001$ & $<0.001$ \\
\hline 6 & 317317.66 & 317187.36 & Did not converge & 0.014 \\
\hline
\end{tabular}

Note. Numbers on bold represent the best fitting values.

Abbreviations: BIC, Bayesian information criterion; ABIC, adjusted Bayesian information criterion; BLRT, bootstrapped likelihood ratio test; LMR, Lo-Mendall-Rubin.

Table 2. Network types among Europeans aged 50 and older by criterion variables: latent class analysis

\begin{tabular}{|c|c|c|c|c|c|}
\hline \multirow[b]{2}{*}{ CRITERION (\%) } & \multicolumn{5}{|c|}{ NETWORK TYPES } \\
\hline & FRIEND-ENHANCED & $C L O S E-F A M I L Y$ & FAMILY-POOR & $M U L T I-T I E$ & $F A M I L Y-R I C H$ \\
\hline Friends & 100.00 & 14.80 & 4.50 & 59.10 & 37.30 \\
\hline Relatives & 44.10 & 12.10 & 57.10 & 37.90 & 54.80 \\
\hline Married & 7.20 & 82.70 & 4.10 & 91.30 & 100.00 \\
\hline 0 children & 39.70 & 11.70 & 45.00 & 14.70 & 16.60 \\
\hline 1 or 2 children & 52.30 & 63.70 & 45.50 & 59.40 & 68.70 \\
\hline $3+$ children & 8.00 & 24.60 & 9.50 & 25.90 & 14.70 \\
\hline Volunteering & 20.70 & 9.80 & 10.80 & 100.00 & 13.40 \\
\hline$\%$ of sample & 10.43 & 49.31 & 11.56 & 5.89 & 22.82 \\
\hline
\end{tabular}

model for use in the subsequent analyses. The five network types thus derived were termed: "friendenhanced," "close-family," "family-poor," "multitie," and "family-rich."

Table 2 shows the relative distribution of the social network characteristics among the five network types. The participants belonging to the "friend-enhanced" network all cited friendship ties, and some cited relatives in their social network as well. They were less likely to be married and tended to have two children or fewer. A relatively high percentage of those in this network type also volunteered. A tenth of the study sample belonged to the "friend-enhanced" network type.

In comparison, almost half of the respondents belonged to the "close-family" network type. The respondents in this class were less likely to mention friends and/or relatives as part of their networks. Most of them were married and had at least one child. Moreover, they had relatively low rates of volunteering.

The third network type, "family-poor," characterized a tenth of the study sample. The respondents belonging to this network constellation mostly cited relatives as their close confidants. They did not mention close friends, however. They were also less likely to be married and did not have many children. In comparison, the "multi-tie" network type represented $6 \%$ of the participants. The respondents in this network grouping tended to report having both friends and relatives as confidants, to be married, and to have many children. They reported volunteering, as well.

The fifth and final network type, "family-rich," constituted the interpersonal environment of a fifth of the study sample. Over half of these respondents reported having relatives as confidants. All were married and most had 1-2 children. However, respondents in this network grouping had relatively low rates of friendship ties and few volunteered.

\section{Covariates}

Our analyses controlled for several variables that could also affect late-life cognition (Ahrenfeldt et al., 2019; Blankevoort et al., 2013; Bond et al., 2006). Age was measured as a continuous variable. Gender was a dichotomous variable. Education was based on the International Standard Classification of Education-1997 classification, dichotomized into secondary education or lower and postsecondary education or higher. Subjective health was measured by asking respondents to rate their own health, with response options ranging from "poor" to "excellent." Responses were coded such 
Table 3. Europeans aged 50 and older: univariate baseline description of the sample background characteristics $(N=50,071)$

\begin{tabular}{|c|c|c|c|c|c|}
\hline CHARACTERISTICS & $N$ & $\%$ & MEAN & SD & RANGE \\
\hline \multicolumn{6}{|l|}{ Gender } \\
\hline Men & 22,031 & 44.0 & & & \\
\hline Women & 28,040 & 56.0 & & & \\
\hline \multicolumn{6}{|l|}{ Education } \\
\hline Secondary or less & 36,643 & 74.7 & & & \\
\hline Post-secondary or more & 12,405 & 25.3 & & & \\
\hline Age & & & 66.0 & 10.1 & $50-103$ \\
\hline Mobility difficulties & & & 1.6 & 2.3 & $0-10$ \\
\hline Self-rated health & & & 2.8 & 1.1 & $1-5$ \\
\hline Immediate recall & & & 5.2 & 1.8 & $0-10$ \\
\hline Delayed recall & & & 3.8 & 2.2 & $0-10$ \\
\hline Fluency & & & 20.1 & 7.5 & $0-45$ \\
\hline
\end{tabular}

that a higher score indicated better health (range $=1-$ 5). Mobility difficulties were measured via the number of mobility, arm function, and fine motor limitations, such as walking 100 meters and climbing one flight of stairs without resting (range $=0-10$ ).

\section{Data analysis}

We performed the analysis in two main steps: first, after having identified the network types, as was explained above, we examined their relationships with the background and cognition variables. Specifically, the classes of the network types and the cognition outcomes were viewed in relation to the respondents' background characteristics and health, specifically age, gender, education, mobility difficulties, and self-rated health. Then, in the second stage of the analysis, we analyzed the profiling of the classes in order to identify how network types are associated with cognitive changes over time. To that end, we regressed the follow-up cognition variables on the network types, while controlling for covariates and the cognition variables at baseline. We used full information maximum likelihood (FIML) for the multivariate analyses. FIML makes use of all available data in model estimation in order to control for potential differential sample attrition effects (Acock, 2005). Insofar as the FIML function is available within the structural equation modeling (SEM) software, we used the Lavaan package for SEM analyses in $\mathrm{R}$ for running the models (Rosseel, 2012).

\section{Results}

A description of the baseline characteristics of the sample is shown in Table 3. As may be seen, the study sample was $56 \%$ women, almost threequarters of respondents had secondary education or less, and their average age was around 65. Participants reported having between one and two mobility limitations, on average, and rated their health as moderately good $(\bar{X}=2.8$; range $=1-5)$. As for the cognitive measures, recall averages (range $=0-10$ ) were 5.3 for immediate recall and almost 4, for delayed recall. The fluency score was about 20, out of a range of $0-45$.

Table 4 shows the sample characteristics by the five network types, including ANOVA tests with Scheffe post hoc comparisons for the significance of the differences between the types. These results demonstrate that while women were almost threequarters of those in the "friend-enhanced" network, they composed only half of those in the "closefamily" network. The "multi-tie" participants were the most educated, the youngest, with the highest health scores and the best cognitive function. The "family-poor" participants, on the other hand, were the least educated, the oldest, and had the worst health and cognition. The "family-rich" respondents had better self-rated physical health and cognitive health compared to those with "friend intensive" and "close family" networks.

In the final and main part of the analysis, we conducted three Ordinary Least Squares (OLS) regression models. The models predicted the different cognitive function indicators at follow-up immediate recall, delayed recall, and fluency. The results of the model are presented in Table 5. Respondents with high scores on the different cognitive variables at baseline also had better scores at the follow-up measurements. The better cognitive function in all three indicators was related to lower age, higher education, and better health. Women had better scores in immediate and delayed recall.

Table 5 also shows the effects of the network types, using the "close-family" type as the reference category. Individuals embedded within the "family- 
Table 4. Socio-demographic, health, and cognition by the five network types: analysis of variance

\begin{tabular}{|c|c|c|c|c|c|c|}
\hline \multirow[b]{2}{*}{ CHARACTERISTICS } & \multirow[b]{2}{*}{ FRIEND-ENHANCED } & \multicolumn{4}{|c|}{ NETWORK TYPES } & \multirow[b]{2}{*}{$F$} \\
\hline & & CLOSE-FAMILY & FAMILY-POOR & $M U L T I-T I E$ & $F A M I L Y-R I C H$ & \\
\hline$N(\%)$ & $\begin{array}{c}5706 \\
(10.06)\end{array}$ & $\begin{array}{l}31,415 \\
(55.37)\end{array}$ & $\begin{array}{l}5402 \\
(9.52)\end{array}$ & $\begin{array}{c}2976 \\
(5.24)\end{array}$ & $\begin{array}{c}11,241 \\
(19.81)\end{array}$ & \\
\hline \multicolumn{7}{|l|}{ Baseline characteristics } \\
\hline$\%$ Women & $73 \%{ }^{a}$ & $49 \% \mathrm{~b}$ & $65 \%$ c & $59 \%{ }^{d}$ & $61 \% \mathrm{~d}$ & $374.44^{* * *}$ \\
\hline$\%$ Post-secondary education & $31 \%^{\mathrm{a}}$ & $22 \%^{\mathrm{b}}$ & $19 \%{ }^{\mathrm{c}}$ & $44 \%{ }^{\mathrm{d}}$ & $27 \% \mathrm{e}^{\mathrm{e}}$ & $220.92^{* * *}$ \\
\hline Age & $66.10^{\mathrm{a}}$ & $66.52^{\mathrm{a}}$ & $69.19^{\mathrm{b}}$ & $62.61^{\mathrm{c}}$ & $63.64^{\mathrm{d}}$ & $348.96^{* * *}$ \\
\hline Self-rated health & $2.84^{\mathrm{a}}$ & $2.75^{\mathrm{b}}$ & $2.53^{c}$ & $3.32^{\mathrm{d}}$ & $2.88^{\mathrm{a}}$ & $269.12^{* * *}$ \\
\hline Mobility difficulties & $1.67^{\mathrm{a}}$ & $1.69^{\mathrm{a}}$ & $2.32^{\mathrm{b}}$ & $0.84^{\mathrm{c}}$ & $1.43^{\mathrm{d}}$ & $206.93^{* * *}$ \\
\hline \multicolumn{7}{|l|}{ Follow-up } \\
\hline Immediate recall & $5.47^{\mathrm{a}}$ & $5.03^{\mathrm{b}}$ & $4.68^{c}$ & $6.04^{\mathrm{d}}$ & $5.50^{\mathrm{a}}$ & $397.26^{* * *}$ \\
\hline Delayed recall & $4.19^{\mathrm{a}}$ & $3.61^{\mathrm{b}}$ & $3.25^{\mathrm{c}}$ & $4.88^{\mathrm{d}}$ & $4.15^{\mathrm{a}}$ & $406.61^{* * *}$ \\
\hline Fluency & $21.09^{\mathrm{a}}$ & $19.61^{\mathrm{b}}$ & $17.97^{\mathrm{c}}$ & $23.17^{\mathrm{d}}$ & $21.03^{\mathrm{a}}$ & $303.67^{* * *}$ \\
\hline
\end{tabular}

Notes. ${ }^{* * *} p<0.001,{ }^{* *} p<0.01,{ }^{*} p<0.05$. Means with differing superscripts (a, b, c, d, and e) within rows are significantly different at the $p<0.05$ based on Scheffe post hoc paired comparisons.

poor" network type had a poorer cognitive function in all three indicators at follow-up, compared to those embedded in a "close-family" network. Those having a "friend-enhanced" network had better function in the immediate recall and delayed recall tasks. Respondents with a "multi-tie" network had better scores in all three cognitive tests. Finally, participants located in "family-rich" networks had better performance in immediate recall and fluency, compared to the "close-family" network type. In sum, respondents belonging to the "family-poor" network had the worse cognitive function over time, in comparison to those in the "close-family" network, while respondents in "friend-enhanced", "multi-tie," and "family-rich" had a better cognitive function.

\section{Discussion}

This study examined the association of social network type with cognitive performance. Our aim was two-fold. First, we sought to identify key network types using the information on contacts with confidants, family structure, and formal social activities. Second, we wished to examine which of the social network constellations were beneficial for cognitive performance and which were related to worsening cognition. Specifically, we explored whether being embedded in networks with more diverse ties, a larger share of friendship ties and a greater social activities is related to a better subsequent cognitive function.

The multi-tie network type, which was endowed with the most diverse and resourceful social ties, emerged as the most beneficial for cognitive performance. This was in accordance with our study hypothesis. The older adults embedded in this type of network were married, had children, cited friends and relatives as confidants, and engaged in volunteering. They also had the best change scores on three cognitive tests at follow-up: immediate recall, delayed recall, and fluency.

This particular outcome might be attributed to the diverse ties and activity engagement found in this network type, which provide a complex environment and varied sources of mental stimulation (Kim and Kim, 2014; Schwartz et al., 2019). Such interactions can act as a form of mental exercise, in accordance with the "use it or lose it" hypothesis (Hultsch et al., 1999). This finding adds to previous research which has identified the advantages of having a diverse network in relation to other domains of health, including functional dependency (Doubova et al., 2010), physical health (Litwin, 1998), and depressive symptomatology (Fiori et al., 2006). Moreover, it supports the contention that having varied social ties and activities is beneficial for overall healthier aging.

Other network types that emerged as beneficial, but to a somewhat lesser degree, were the "friendenhanced" and the "family-rich" network types. The respondents in these network settings were characterized by either ties and social activities outside of the family circle or by ties with varied family members (i.e. spouse, children, and other relatives). This finding further strengthens the claim that the complexity of an enriched social environment may facilitate improved cognitive aging (Ellwardt et al., 2015; Hertzog et al., 2009). Older adults who have more sources of mental stimulation, family or non-family, can benefit from environments that are more cognitively demanding and which require handling and switching between multiple contexts. They might 
Table 5. OLS models predicting immediate recall, delayed recall and fluency among Europeans aged 50 and older using the network types and controlling background characteristics

\begin{tabular}{|c|c|c|c|c|c|c|}
\hline \multirow[b]{2}{*}{ BASELINE CHARACTERISTICS } & \multicolumn{2}{|c|}{$\begin{array}{c}\text { IMMEDIATE RECALL - } \\
\text { FOLLOW-UP }\end{array}$} & \multicolumn{2}{|c|}{$\begin{array}{c}\text { DELAYED RECALL - } \\
\text { FOLLOW-UP }\end{array}$} & \multicolumn{2}{|c|}{ FLUENCY - FOLLOW-UP } \\
\hline & $B(S E)$ & BETA & $B(S E)$ & BETA & $B(S E)$ & BETA \\
\hline Baseline dependent variable & $0.39(0.00)$ & $0.39^{* * *}$ & $0.42(0.01)$ & $0.40^{* * *}$ & $0.51(0.01)$ & $0.50 * * *$ \\
\hline Age & $-0.04(0.00)$ & $-0.22^{* * *}$ & $-0.05(0.00)$ & $-0.22^{* * *}$ & $-0.13(0.00)$ & $-0.17^{* * *}$ \\
\hline Women & $0.21(0.02)$ & $0.05^{* * *}$ & $0.26(0.02)$ & $0.06^{* * *}$ & $0.07(0.06)$ & 0.01 \\
\hline Education & $0.44(0.02)$ & $0.10^{* * *}$ & $0.51(0.02)$ & $0.10^{* * *}$ & $1.42(0.07)$ & $0.08^{* * * *}$ \\
\hline Self-rated health & $0.08(0.01)$ & $0.05^{* * *}$ & $0.11(0.01)$ & $0.05^{* * *}$ & $-0.40(0.03)$ & $0.06^{* * *}$ \\
\hline Mobility difficulties & $-0.05(0.00)$ & $-0.06^{* * *}$ & $-0.05(0.01)$ & $-0.05^{* * *}$ & $-0.15(0.03)$ & $-0.05^{* * *}$ \\
\hline \multicolumn{7}{|l|}{ Network types: } \\
\hline Friend-enhanced ${ }^{1}$ & $0.08(0.02)$ & $0.01^{* * *}$ & $0.11(0.03)$ & $0.02^{* * *}$ & $0.17(0.09)$ & 0.01 \\
\hline Family-poor ${ }^{1}$ & $-0.11(0.03)$ & $-0.02^{* * *}$ & $-0.10(0.03)$ & $-0.01^{* *}$ & $-0.34(0.10)$ & $-0.01^{* * *}$ \\
\hline Multi-tie $^{1}$ & $0.17(0.03)$ & $0.02^{* * *}$ & $0.22(0.04)$ & $0.02^{* * *}$ & $0.88(0.13)$ & $0.03^{* * *}$ \\
\hline Family-rich $^{1}$ & $0.05(0.02)$ & $0.01^{*}$ & $0.03(0.03)$ & 0.01 & $0.19(0.08)$ & $0.01^{*}$ \\
\hline Observations & \multicolumn{2}{|c|}{50,071} & \multicolumn{2}{|c|}{50,071} & \multicolumn{2}{|c|}{50,071} \\
\hline$R$-squared & \multicolumn{2}{|c|}{0.41} & \multicolumn{2}{|c|}{0.41} & \multicolumn{2}{|c|}{0.50} \\
\hline
\end{tabular}

Note: All models controlled for country.

${ }^{1}$ Reference: "close-family."

${ }^{* * * *} p<0.001,{ }^{* *} p<0.01,{ }^{*} p<0.05$.

also benefit from being physically active and in better mental health, due to these varied social engagements (Cohn-Schwartz, 2020). However, the greater effects of the "multi-tie" network suggest that it is preferable to have both family and nonfamily ties, insofar as this social constellation provides the most complex and diverse social environment.

Our finding of a positive effect of the "friendenhanced" network type on cognition, as described above, is in contrast to that of the study by Kim and Lee (2019) in South Korea. In that study, the worst cognitive function was seen among the widowed network which, similar to our "friend-enhanced" network type, was characterized by not being married and having a high frequency of contact with friends. A possible explanation for this discrepancy is that among European adults, friends might play a more important role in providing mental stimulation and novel experiences (Aartsen et al., 2004; Schwartz and Litwin, 2019). Clearly, more research is needed on cultural differences in the effects of social network types on cognitive decline.

Perhaps most significantly, our study found that older adults embedded in "family-poor" networks had the worst cognitive function over time. These respondents were less likely to be married, had fewer children, did not cite having friends, and tended to name other relatives as their main confidants. Thus, having other relatives as one's primary close ties, without maintaining additional sources of close relationships, seemed to be the most detrimental interpersonal environment for cognitive health among the older adults in the sample, across the respective social network types. It could be that relatives provide less frequent interactions and a more minimal variety of activities, with the concomitant lesser cognitive stimulation that results. Additionally, the older adults in such "familypoor" networks lack other close ties or activities that might be able to augment the stimulation they receive.

Some potential shortcomings of the present analysis should be noted. One such limitation is that the study focused on the effects of network type on cognition and did not examine the other direction, in which cognition may possibly affect social network type. Some previous findings have shown that both processes may be at play (Kelly et al., 2017). Nevertheless, our longitudinal findings do support the claim of temporal dynamics between network type and future cognition, even if the opposite direction might also be relevant. Future research should delve more deeply into the reciprocal temporal associations between these constructs.

Another possible limitation is that the variables used to construct the network types in this study did not include some other potentially interesting criterion variables, for example, participation in religious activities. This may have limited our ability to identify church-oriented congregant networks, similar to those found in other cultural settings such as South Korea and the U.S.A. (Kim and Lee, 2019; Litwin and Shiovitz-Ezra, 2011). This limitation is minor, 
however, insofar as European societies are relatively secular (Halman and Draulans, 2006).

We also did not relate in the construction of the network types to the strength or frequency of the contacts. By definition, spousal and close-family relations are considered to be strong ties (Granovetter, 1977; Litwin and Stoeckel, 2014), while formal social activity, such as volunteering, typically exemplifies weak ties. Previous research has rarely explicitly examined the role of weak ties in relation to cognition. For an exception see Pan and Chee (2020), who hypothesize that weak ties positively affect cognition because they provide novel and stimulating experiences. Our findings of the importance of tie diversity could reflect a similar mechanism - it is beneficial to have different types of ties, as they can provide varied stimulation and experiences. Future research could benefit from a more direct examination of weak and strong ties, as well as creating typologies of such ties.

A final minor shortcoming is that the control variables in our study did not take household composition into account. It might be that living with children and grandchildren, which is more common in the Southern European countries (Iacovou and Skew, 2011), is related to cognitive health in older age. This particular shortcoming is minimized in the present analysis, however, insofar as country differences were controlled in the regressions. Nevertheless, the association of household composition with the cognitive function is a topic worthy of further exploration.

The present study also has several strengths of note. These include its longitudinal design, the very large sample, and the utilization of LCA for the derivation of the social network types. Further inquiry into the domain addressed here is strongly recommended. In addition to the strengths of the study, our paper uniquely adds to the growing literature on the effect of social relationships on cognition in later life. We underscore the importance of being integrated into a diverse array of social ties. Our paper adds to factors already known to prevent or delay cognitive declines, such as reading activity (Chang et al., 2020) and cognitive leisure activity (Ihle, Gouveia, et al., 2020). Our study also adds to a recent publication that showed that friendship ties are beneficial for cognition (Ihle, Oris, et al., 2020). We add to it by emphasizing that having more types of ties, in addition to friends, is preferred.

In conclusion, this study suggests that having varied sources of network ties is beneficial not only to physical and mental health, but also to the cognitive health of older adults. It also underscores the importance for the cognitive function of having friendship ties or social networks that are characterized by several types of family relationships.
In contrast, the study findings suggest that "family-poor" networks, i.e. those based mainly on ties with relatives other than spouse and children, have poorer cognition over time. Thus, mental health practitioners should pay particular attention to older adults whose close relationships are mostly with "other" family members (not partner or children), and who exhibit little social involvement outside of the more distant family circle. These adults might face an increased risk for cognitive decline and should receive assistance in enhancing their social involvement.

\section{Conflict of interest}

None declared.

\section{Description of authors' roles}

E. Cohn-Schwartz designed the study, performed some of the statistical analyses, and wrote the final manuscript. M. Levinsky constructed the analytical sample and performed the statistical analyses. $\mathrm{H}$. Litwin gave critical comments, assisted in the writing process, and edited the final manuscript.

\section{Acknowledgments}

The SHARE data collection has been primarily funded by the European Commission through FP5 (QLK6-CT-2001-00360), FP6 (SHARE-I3: RIICT-2006-062193, COMPARE: CIT5-CT-2005028857, SHARELIFE: CIT4-CT-2006-028812), and FP7 (SHARE-PREP: No. 211909, SHARELEAP: No. 227822, SHARE M4: No. 261982). Additional funding from the German Ministry of Education and Research, the Max Planck Society for the Advancement of Science, the U.S. National Institute on Aging (U01_AG09740-13S2, P01_ AG005842, P01_AG08291, P30_AG12815, R21_AG025169, Y1-AG-4553-01, IAG_BSR0611, OGHA_04-064, HHSN271201300071C), and from various national funding sources is gratefully acknowledged (see www.share-project.org).

\section{References}

Aartsen, M. J., van Tilburg, T., Smits, C. H. M. and Knipscheer, K. C. P. M. (2004). A longitudinal study of the impact of physical and cognitive decline on the personal network in old age. Fournal of Social and Personal Relationships, 21, 249-266. https://doi.org/10.1177 /0265407504041386. 
Acock, C. A. (2005). Working with missing values. Fournal of Marriage and Family, 67, 1012-1028.

Ahrenfeldt, L. J. et al. (2019). Gender differences in cognitive function and grip strength: a cross-national comparison of four European regions. European fournal of Public Health, 29, 667-674. https://doi.org/10.1093/eurpub /cky266.

Aichele, S. and Ghisletta, P. (2018). Memory deficits precede increases in depressive symptoms in later adulthood. The fournals of Gerontology: Series B, 74, 943-953. https://doi.org/10.1093/geronb/gbx183.

Blankevoort, C. G. et al. (2013). Physical predictors of cognitive performance in healthy older adults: a crosssectional analysis. PLoS One, 8, e70799. https://doi.org/10 .1371 /journal.pone.0070799.

Bond, J., Dickinson, H. O., Matthews, F., Jagger, C. and Brayne, C. (2006). Self-rated health status as a predictor of death, functional and cognitive impairment: a longitudinal cohort study. European fournal of Ageing, 3, 193-206. https:// doi.org/10.1007/s10433-006-0039-8.

Börsch-Supan, A. et al. (2013). Data resource profile: the Survey of Health, Ageing and Retirement in Europe (SHARE). International Fournal of Epidemiology, 42, 992-1001. https://doi.org/10.1093/ije/dyt088.

Chang, Y., Wu, I. and Hsiung, C. A. (2020). Reading activity prevents long-term decline in cognitive function in older people: evidence from a 14-year longitudinal study. International Psychogeriatrics, 1-12. https://doi.org/10.1017 /S1041610220000812.

Cheke, L. G. and Clayton, N. S. (2013). Do different tests of episodic memory produce consistent results in human adults? Learning $\mathcal{E}$ Memory, 20, 491-498. https://doi.org /10.1101/lm.030502.113.

Clark, L. J. et al. (2009). Longitudinal verbal fluency in normal aging, preclinical, and prevalent Alzheimer's disease. American fournal of Alzheimer's Disease and Other Dementias, 24, 461-468. https://doi.org/10.1177 $/ 1533317509345154$.

Cohn-Schwartz, E. (2020). Pathways from social activities to cognitive functioning: the role of physical activity and mental health. Innovation in Aging, 4, igaa015. https://doi .org/10.1093/geroni/igaa015.

Crooks, V. C., Lubben, J., Petitti, D. B., Little, D. and Chiu, V. (2008). Social network, cognitive function, and dementia incidence among elderly women. American Fournal of Public Health, 98, 1221-1227. https://doi.org/10 .2105/AJPH.2007.115923.

Dal Bianco, C., Garrouste, C. and Paccagnella, $O$. (2013). Early-life circumstances and cognitive functioning dynamics in later life. In: A. Börsch-Supan, M. Brandt, H. Litwin and G. Weber (Eds.), Active ageing and solidarity between generations in Europe: First results from SHARE after the economic crisis (pp. 209-223). Munich: MEA, Max Planck Institute for Social Law and Social Policy.

Deary, I. J. et al. (2009). Age-associated cognitive decline. British Medical Bulletin, 92, 135-52. https://doi.org/10.1093 /bmb/ldp033.

Dewey, M. E. and Prince, M. J. (2005). Cognitive Function. In: A. Börsch-Supan, A. Brugiavini, H. Jürges, J. Mackenbach, J. Siegrist and G. Weber (Eds.), Health, ageing and retirement in Europe - First results from the Survey of Health, Ageing and Retirement in Europe (pp. 118-125).
Mannheim: Mannheim Research Institute for the Economics of Aging (MEA).

Djundeva, M., Dykstra, P. A. and Fokkema, T. (2018). Is living alone "aging alone"? Solitary living, network types, and well-being. The fournals of Gerontology: Series B, 74, 1406-1415. https://doi.org/10.1093/geronb/gby119.

Doubova, S. V., Espinosa-Alarcán, P. and FloresHernndez, S. (2010). Social network types and functional dependency in older adults in Mexico. BMC Public Health, 10. https://doi.org/10.1186/1471-245810-104.

Ellwardt, L., Van Tilburg, T. G. and Aartsen, M. J. (2015). The mix matters: complex personal networks relate to higher cognitive functioning in old age. Social Science $\mathcal{E}$ Medicine, 125, 107-115. https://doi.org/10.1016/j .socscimed.2014.05.007.

Ertel, K. A., Glymour, M. M. and Berkman, L. F. (2008). Effects of social integration on preserving memory function in a nationally representative US elderly population. American fournal of Public Health, 98, 1215-1220. https://doi .org/10.2105/AJPH.2007.113654.

Fiori, K. L., Antonucci, T. C. and Cortina, K. S. (2006). Social network typologies and mental health among older adults. The fournals of Gerontology, Series B: Psychological Sciences and Social Sciences, 61, P25-P32. https://doi.org/10 .1093/geronb/61.1.P25.

Fiori, K. L., Smith, J. and Antonucci, T. C. (2007). Social network types among older adults: a multidimensional approach. The fournals of Gerontology, Series B: Psychological Sciences and Social Sciences, 62, 322-330.

Granovetter, M. S. (1977). The strength of weak ties. In: S. Leinhardt (Ed.), Social Networks (pp. 347-367). New York: Academic Press.

Halman, L. and Draulans, V. (2006). How secular is Europe? British fournal of Sociology, 57, 263-288. https://doi .org/10.1111/j.1468-4446.2006.00109.x.

Haugrud, N., Crossley, M. and Vrbancic, M. (2011). Clustering and switching strategies during verbal fluency performance differentiate Alzheimer's disease and healthy aging. Fournal of the International Neuropsychological Society, 17, 1153-1157. https://doi.org/10.1017 /S1355617711001196.

Hertzog, C., Kramer, A. F., Wilson, R. S. and Lindenberger, U. (2009). Enrichment effects on adult cognitive development. Psychological Science in the Public Interest, 9, 1-65. https://doi.org/10.1111/j.1539-6053.2009 $.01034 . \mathrm{x}$.

Hughes, T. F., Flatt, J. D., Fu, B., Chang, C. C. H. and Ganguli, M. (2013). Engagement in social activities and progression from mild to severe cognitive impairment: the MYHAT study. International Psychogeriatrics, 25, 587-595. https://doi.org/10.1038/mp.2011.182.doi.

Hultsch, D. F., Hertzog, C., Small, B. J. and Dixon, R. A. (1999). Use it or lose it: engaged lifestyle as a buffer of cognitive decline in aging? Psychology and Aging, 14, 145-263.

Iacovou, M. and Skew, A. J. (2011). Household composition across the new Europe: where do the new Member States fit in? Demographic Research, 25, 465-490. https://doi.org/10.4054/DemRes.2011. 25.14 . 
Ihle, A., Gouveia, É. R. et al. (2020). The relation of education, occupation, and cognitive activity to cognitive status in old age: the role of physical frailty. International Psychogeriatrics, 29, 1469-1474. https://doi.org/10.1017 /S1041610217000795.

Ihle, A., Oris, M. et al. (2020). The longitudinal relation between social reserve and smaller subsequent decline in executive functioning in old age is mediated via cognitive reserve. International Psychogeriatrics, 1-7. https://doi.org/10 $.1017 /$ S1041610219001789.

Kelly, M. E. et al. (2017). The impact of social activities, social networks, social support and social relationships on the cognitive functioning of healthy older adults: a systematic review. Systematic Reviews, 6, 259. https://doi.org /10.1186/s13643-017-0632-2.

Kim, E. Y. and Kim, K. W. (2014). A theoretical framework for cognitive and non-cognitive interventions for older adults: stimulation versus compensation. Aging $\mathcal{E}$ Mental Health, 18, 304-315. https://doi.org/10.1080/13607863 .2013.868404.

Kim, Y. B. and Lee, S. H. (2019). Social network types and cognitive decline among older Korean adults: a longitudinal population-based study. International fournal of Geriatric Psychiatry, 34, 1845-1854. https://doi.org/10.1002/gps.5200.

Litwin, H. (1998). Social network type and health status in a national sample of elderly Israelis. Social Science and Medicine, 46, 599-609. https://doi.org/10.1016/S02779536(97)00207-4.

Litwin, H. (2001). Social network type and morale in old age. The Gerontologist, 41, 516-524.

Litwin, H., Levinsky, M. and Schwartz, E. (2020). Network type, transition patterns and well-being among older Europeans. European fournal of Ageing, 17, 241-250. https://doi.org/10.1007/s10433-01900545-7.

Litwin, H. and Shiovitz-Ezra, S. (2006). Network type and mortality risk in later life. Gerontologist, 46, 735-743. https:// doi.org/10.1093/geront/46.6.735.

Litwin, H. and Shiovitz-Ezra, S. (2011). Social network type and subjective well-being in a national sample of older Americans. The Gerontologist, 51, 379-388. https://doi.org /10.1093/geront/gnq094.
Litwin, H. and Stoeckel, K. J. (2014). Confidant network types and well-being among older Europeans. The Gerontologist, 54, 762-772. https://doi.org/10.1093/geront/ gnt056.

Luppa, M. et al. (2009). Prediction of institutionalization in the elderly. A systematic review. Age and Ageing, 39, 31-38. https://doi.org/10.1093/ageing/afp202.

Nylund, K. L., Asparouhov, T. and Muthen, B. O. (2008). Deciding on the number of classes in latent class analysis and growth mixture modeling: a Monte Carlo simulation study. Structural Equation Modeling: $A$ Multidisciplinary fournal, 15, 182. https://doi.org/10.1080 /10705510701575396.

Pan, X. and Chee, K. H. (2020). The power of weak ties in preserving cognitive function: a longitudinal study of older Chinese adults. Aging E Mental Health, 24, 1046-1053. Routledge. https://doi.org/10.1080/13607863.2019 .1597015 .

Park, D. C. and Reuter-Lorenz, P. (2009). The adaptive brain: aging and neurocognitive scaffolding. Annual Review of Psychology, 60, 173-196. https://doi.org/10.1146 /annurev.psych.59.103006.093656.

Rosseel, Y. (2012). lavaan: an R package for structural equation modeling. Fournal of Statistical Software, 48, 1-36. https://doi.org/10.18637/jss.v048.i02.

Schupf, N. et al. (2005). Decline in cognitive and functional skills increases mortality risk in nondemented elderly. Neurology, 65, 1218-1226. https://doi.org/10.1212/01.wnl $.0000180970 .07386 . c b$.

Schwartz, E., Khalaila, R. and Litwin, H. (2019). Contact frequency and cognitive health among older adults in Israel. Aging and Mental Health, 23, 1008-1016. https://doi.org $/ 10.1080 / 13607863.2018 .1459472$.

Schwartz, E. and Litwin, H. (2019). Changes in social networks and cognitive decline. In: A. Börsch-Supan, J. Bristle, K. Andersen-Ranberg, A. Brugiavini, F. Jusot, H. Litwin and G. Weber (Eds.), Health and socio-economic status over the life course. First results from SHARE Waves 6 and 7 (pp. 219-225). Berlin/Boston: De Gruyter.

Wenger, C. G. (1991). A network typology: from theory to practice. Fournal of Aging Studies, 5, 147-162. 